\title{
Risk factors for excessively prolonged meropenem use in the intensive care setting: a case-control study
}

\author{
Juri Katchanov ${ }^{1 *}$, Benno Kreuels ${ }^{2,5+}$, Florian P. Maurer ${ }^{3}$, Kai Wöstmann ${ }^{4}$, Johannes Jochum² ${ }^{2}$ Christina König ${ }^{1,4}$, \\ Kariem Seoudy ${ }^{4}$, Holger Rohde ${ }^{3}$, Ansgar W. Lohse ${ }^{2}$, Dominic Wichmann ${ }^{1}$, Michael Baehr ${ }^{4}$, Camilla Rothe ${ }^{2}$ \\ and Stefan Kluge
}

\begin{abstract}
Background: Inappropriate use of broad-spectrum antimicrobials affects adversely both the individual patient and the general public. The aim of the study was to identify patients at risk for excessively prolonged carbapenem treatment in the ICU as a target for antimicrobial stewardship interventions.

Methods: Case-control study in a network of 11 ICUs of a university hospital. Patients with uninterrupted meropenem therapy $(\mathrm{MT})>4$ weeks were compared to controls. Controls were defined as patients who stayed on the ICU $>4$ weeks and received meropenem for $\leq 2$ weeks. Associations between case-control status and potential risk factors were determined in a multivariate logistic regression model.

Results: Between $1^{\text {st }}$ of January 2013 and $31^{\text {st }}$ of December 2015, we identified 36 patients with uninterrupted MT > 4 weeks. Patients with prolonged MT were more likely to be surgical patients ( $72.2 \%$ of cases vs. $31.5 \%$ of controls; $p \leq 0.001)$ with peritonitis being the most common infection $(n=16,44.4 \%)$. In the multivariate logistic regression model colonization with multidrug-resistant (MDR) Gram-negative bacteria (OR 7.52; 95\% Cl 1.88-30.14, $p=0.004$ ) and the type of infection (peritonitis vs. pneumonia: OR 16.96, 95\% Cl 2.95-97.49) were associated with prolonged MT.
\end{abstract}

Conclusion: Surgical patients with peritonitis and patients with known colonization with MDR Gram-negative bacteria are at risk for excessively prolonged carbapenem therapy and represent an important target population for antimicrobial stewardship interventions.

Keywords: Antimicrobial use, Antimicrobial stewardship, Broad-spectrum antibiotics

\section{Background}

Antibiotics are among the most frequently prescribed drugs in intensive care settings [1]. Administration of antibiotics in patients has been shown to be an important risk factor for the emergence of colonization and infection with antibiotic-resistant bacteria [1-4]. Furthermore, prolonged use of antimicrobials is associated with Clostridium difficile infection, antibiotic-related adverse events, and increased health care costs [2].

\footnotetext{
* Correspondence: j.katchanov@uke.de

${ }^{\dagger}$ Equal contributors

${ }^{1}$ Department of Intensive Care Medicine, University Medical Center

Hamburg-Eppendorf, Martinistr. 52, 20246 Hamburg, Germany

Full list of author information is available at the end of the article
}

Prolonged use of broad-spectrum antibiotics such as carbapenems is particularly worrying as it promotes the spread of multidrug-resistant, difficult-to-treat pathogens.

In the present study, we analysed retrospectively patients treated with meropenem in a large centre for intensive care medicine in a German university hospital. We sought to describe the characteristics of patients having received excessively prolonged meropenem treatment, defined as uninterrupted therapy $>4$ weeks, their microbiological data, and outcome on the ICU. We chose the duration of $>4$ weeks as it indicates an inappropriately long use of a broad-spectrum antimicrobial not supported by any guideline or local standard procedure. Our aims were i) to understand risk factors 
for excessively prolonged treatment with a carbapenem and ii) to identify target populations for pre-emptive antimicrobial stewardship interventions.

\section{Methods}

The University Medical Center Hamburg-Eppendorf is a tertiary level medical centre with approx. 1600 hospital beds and 80,000 admissions per year. The Department of Intensive Care includes 11 ICUs with a capacity of 132 beds. Approximately 8,000 patients are admitted to the ICUs each year, with an average length of stay on the ICU of 4.5 days. All decisions to initiate or to discontinue antimicrobial treatment are taken by the ICU consultants.

Meropenem was the only hospital-listed standard carbapenem during the study period ( $1^{\text {st }}$ of January 2013 until $31^{\text {st }}$ of December 2015). In selected cases, imipenem/cilastin was used on special request. These cases were excluded from further analysis, as they did not represent the standard prescription policy and made up less than $7 \%$ of all carbapenem prescriptions. Doripenem and ertapenem were not used during the study period.

\section{Patient identification from database}

Basic data on all ICU patients who received meropenem during the study period were retrieved from the electronic medical records (ICM, Dräger, Lübeck, Germany). Patients were grouped according to the length of ICU stay ( $\leq 1$ day, $>1$ to 3 days, $>3$ to 7 days, $>7$ to 14 days, $>14$ to 28 days, and $>28$ days). The following information was additionally retrieved for patients who remained in the ICU for longer than 4 weeks: age (grouped as $<50,50-70$ and $>70$ for regression analysis), sex, main diagnosis defined as the main reason for ICU admission (grouped as medical, surgical, neurosurgical-neurological), presence of malignancy, Simplified Acute Physiology Score (SAPS score, grouped as below median $(<40)$ and above median $(\geq 40)$ for regression analysis), antibiotic treatment, surgical procedures including re-operation to obtain source control, results of source control management and outcome in the ICU.

\section{Case-control design}

Cases were defined as patients who stayed on the ICU longer than 4 weeks and received meropenem for longer than 4 weeks without interruption. If a patient was on meropenem therapy while being transferred to the ICU, the duration of meropenem therapy before admission was added to the duration of therapy during the ICU stay.

Controls were defined as patients who stayed on the ICU longer than 4 weeks and were treated with meropenem for 2 weeks or less. Meropenem therapy (MT) for $\leq$ 2 weeks was used as a marker for guideline-adherent prescription for ventilator-associated pneumonia, urinary tract infection and peritonitis [5-8]. To attain optimal statistical power, 108 controls were randomly selected from 322 patients fulfilling the definition (3:1 ratio of controls to cases) by use of a random number generator.

\section{Data on antimicrobial resistance}

All available microbiological data generated during the hospital stay were collected for patients included in the study. In addition, all patients were screened on admission to the ICU for colonization with the following bacteria: nasal swab for methicillin-resistant $S$. aureus (MRSA), wound swabs for MRSA, pharyngeal and deep anal (anorectal) swabs for vancomycin-resistant enterococci (VRE) and multidrug-resistant (MDR) Gram-negative bacteria. MDR Gram-negative bacteria (MRGN) were defined as 3MRGN or 4MRGN in accordance to the current definition by the German national public health institute (Robert Koch Institute). In brief, Enterobacteriaceae are defined as 3MRGN when resistant to ureidopenicillin/beta-lactamase inhibitor combinations (e.g. piperacillin/tazobactam), third generation cephalosporins (e.g. ceftriaxone) and fluoroquinolones (e.g. ciprofloxacin), but susceptible to carbapenems (e.g. meropenem). 4MRGN Enterobacteriaceae are defined as being resistant to ureidopenicillins/beta-lactamase inhibitor combinations, third generation cephalosporins, fluoroquinolones and carbapenems.

\section{Statistical analysis}

Summary statistics for the study participants were expressed as proportions for dichotomous or categorical variables with a corresponding $\mathrm{Chi}^{2}$ test and as medians with interquartile range (IQR) for continuous variables with a corresponding Wilcoxon rank-sum test.

Possible associations between case-control status and potential risk factors were determined by calculating odds ratios (OR) and 95\% confidence intervals (CI). In a first step, analysis was performed as univariate logistic regression with the case-control status as independent variable and potential risk factors as dependent variables (i.e. age, sex, main reason for ICU admission, presence of malignancy, SAPS score, colonization with carbapenem-susceptible, MDR bacteria, type of infection). All variables showing at least some evidence of an association with case-control status (defined as $\mathrm{p}<0.1$ ) were then included in a multivariate logistic regression model to adjust for potential confounding. All data analyses were performed with Stata 12 (StataCorp LP, College Station, USA).

\section{Results}

\section{Selection of cases and controls}

In total, 3,909 patients admitted to the ICUs during the study period were treated with meropenem. The proportion of meropenem prescriptions increased with increasing length of stay (LOS), ranging from $6.4 \%$ in patients staying between 24 and $72 \mathrm{~h}$ to $86.1 \%$ (606/704 patients) 
in patients with an ICU LOS of longer than 4 weeks (Fig. 1). 322 patients with ICU LOS $>4$ weeks received uninterrupted MT $\leq 2$ weeks, and 108 of these patients were randomly selected as controls (Fig. 2). 36 patients received uninterrupted MT for longer than 4 weeks. One patient received meropenem twice during admission and the longer episode was counted.

\section{Characteristics of cases and controls}

The characteristics of cases and controls are summarized in Table 1. There were no differences in age, sex, and simplified acute physiologic score (SAPS) at admission. Cases were more likely to be surgical patients $(72.2 \%$ of cases vs. $31.5 \%$ of controls; $\mathrm{p} \leq 0.001$ ), while controls were more likely to be patients with medical conditions (11.1\% of cases vs. $42.7 \%$ of controls; $p=0.001$ ). None of the surgical patients with peritonitis was considered to have the source of the abdominal infection adequately controlled. This fact is reflected by the very high number of re-operations in this group. Cases suffered more often then controls from a malignant disease $(47.2 \%$ of cases vs. $20.4 \%$ of controls; $\mathrm{p}=0.002$ ). All malignancies in the prolonged MT were solid tumours $(\mathrm{n}=17)$, whereas in controls 4 patients had a haematological malignancy and 18 patients a solid tumour.

Cases were colonized with 3MRGN bacteria more often than controls $(\mathrm{p}=0.007)$ and had a higher mortality on ICU $(\mathrm{p}=0.03)$.

\section{Risk factors for prolonged MT}

Univariate logistic regression showed an association between prolonged MT and the presence of malignancy (OR

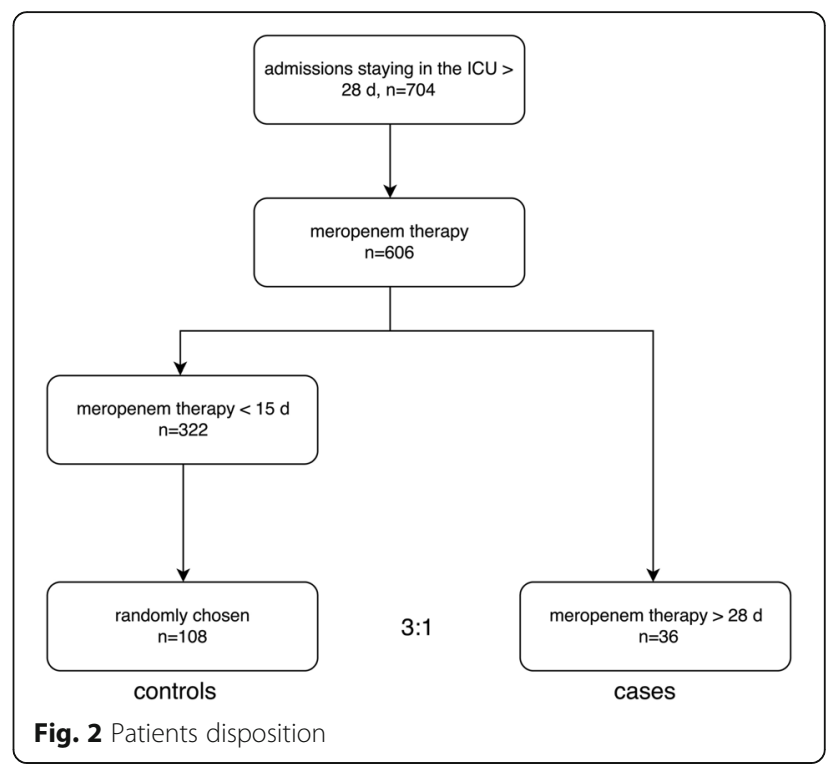

3.5; 95\% CI 1.57-7.82, $\mathrm{p}=0.002$ ), colonization with multidrug-resistant carbapenem-susceptible Gram-negative bacteria (OR 4.12; 95\% CI 1.38-12.35, $\mathrm{p}=0.01$ ), being a surgical patient as compared to being a medical patient (OR 8.36, 95\% CI 2.67-26.17, $\mathrm{p}<0.001$ ) and the type of infection $(\mathrm{p}<0.001)$ with a strongly increased risk for patients with peritonitis compared to patients with pneumonia (OR 21.60, 95\% CI 5.05-92.35). No association was seen for age $(\mathrm{p}=0.44)$, sex $(\mathrm{p}=0.76)$ and SAPS score $(\mathrm{p}=0.33)$ at admission. In the multivariate logistic regression model colonization with carbapenem-susceptible, multidrugresistant Enterobacteriaceae (OR 7.52; 95\% CI 1.88-30.14,

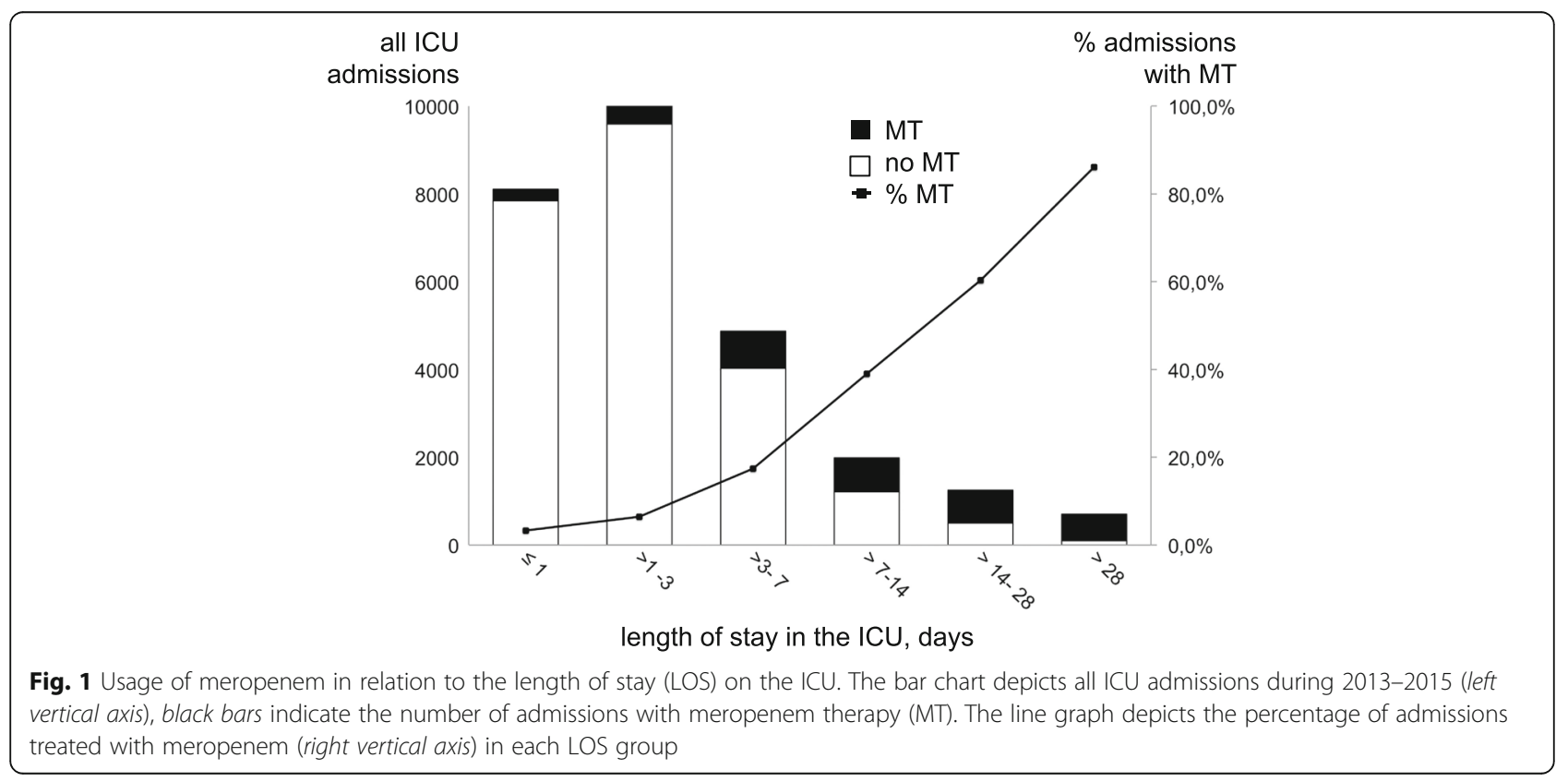


Table 1 Clinical characteristics of patients with prolonged meropenem therapy $(\mathrm{MT})>4$ weeks and controls (ICU-stay $>$ 4 weeks and meropenem therapy $\leq 14$ days)

\begin{tabular}{llll}
\hline & Cases $^{\mathrm{a}}$ & Controls $^{\mathrm{b}}$ & $p$ \\
\hline Number of patients & 36 & 108 & \\
$\begin{array}{l}\text { Duration of uninterrupted meropenem } \\
\text { use, days, median (IQR) }\end{array}$ & $34(31-39)$ & $9(7-11)$ & $<0.001$ \\
Age in years, median (IQR) & $63(51-71)$ & $66(56-73)$ & 0.26 \\
Female sex, $n$ (\%) & $13(36.1)$ & $36(33.3)$ & 0.76 \\
Days on ICU, median (IQR) & $66(51.5-92.5)$ & $35(31-45)$ & $<0.001$ \\
Malignancy, $n$ (\% of all pts) & $17(47.2)$ & $22(20.4)$ & 0.002 \\
SAPS score at admission, median (IQR) & $42(35-48)$ & $39(33-47)$ & 0.36 \\
Medical patients, $n$ (\% of all pts) & $4(11.1)$ & $45(42.7)$ & 0.001 \\
Neurological patients, $n$ (\% of all pts) & $6(16.7)$ & $30(26.9)$ & 0.22 \\
Surgical patients, $n$ (\% of all pts) & $26(72.2)$ & $34(31.5)$ & $<0.001$ \\
Number of operations, median (IQR) & $14(5-27)$ & $4(3-7)$ & $<0.001$ \\
Colonization/infection with & $7(19.4)$ & $7(6.5)$ & 0.007
\end{tabular}

carbapenem-susceptible, multidrug-

resistant Enterobacteriaceae $n$ (\%)

Type of infection, $n(\%)$

$\begin{array}{llll}\text { pneumonia } & 4(11.1) & 27(25.0) & <0.001 \\ \text { peritonitis } & 16(44.4) & 5(4.6) & \\ \text { mediastinitis } & 6(16.7) & 4(3.7) \\ \text { unclear focus } & 10(27.8) & 72(66.7) & \\ \text { In-ICU-mortality, n (\%) } & 16(44.4 \%) & 27(25.0 \%) & 0.03\end{array}$

apatients with ICU stay $>4$ weeks and MT $>28$ days

${ }^{\mathrm{b}}$ patients with ICU stay $>4$ weeks and MT $\leq 14$ days

in surgical patients

Abbreviations: IQR: interquartile range SAPS: simplified acute physiology score MT: meropenem therapy

$\mathrm{p}=0.004$ ) and the type of infection (peritonitis vs. pneumonia: OR 16.96, 95\% CI 2.95-97.49) were associated with prolonged MT (Table 2).

\section{Microbiological data}

In the prolonged MT group, 6 patients were colonized with 3MRGN E. coli and 1 patient with 3MRGN $K$. pneumonia. In the control group, 4 patients were colonized with 3MRGN E. coli, 2 patients with 3MRGN $K$. pneumoniae and 1 patient with 3MRGN $K$. oxytoca. One patient in the prolonged MT group colonized with 3MRGN E. coli and carbapenem-susceptible Enterobacter cloacae developed colonization with carbapenemresistant E.coli and E. cloacae during prolonged MT. In one patient from the prolonged MT group, emergence of carbapenem-resistant $P$. aeruginosa was detected during MT (anal swab).

Bacterial isolates detected in intraoperative specimens, blood and cerebrospinal fluid (CSF) cultures of patients with prolonged MT are summarized in Table 3.

\section{Discussion}

In our study, surgical patients with intra-abdominal infections were at risk for excessively prolonged meropenem use. The majority of the patients presented with an anastomotic leak requiring repetitive surgical interventions for source control. Around half of the patients had an initial surgical procedure for gastrointestinal malignancy.

The duration of antimicrobial therapy in complicated intra-abdominal infection has been recently studied in a large randomized controlled trial [9]. In patients with an adequate source control procedure, the outcomes after fixed-duration antibiotic therapy of 4 days did not differ from those after a longer course of antibiotics of 8 days [9]. In our patients, repetitive surgery reflected difficulties in source control and the presence of persistent peritonitis. The duration of antibiotic therapy for persistent peritonitis is not well established [10], the recommendation in Germany being 7 to 10 days [8]. A longer duration of antibiotic therapy for intra-abdominal infections is an independent risk factor for subsequent intra-abdominal infections and associated with increased mortality [11].

According to the guidelines of Infectious Diseases Society of America (IDSA) empiric antibiotic therapy for health care-associated intra-abdominal infection should be driven by local microbiology results [12]. In the era of multidrug-resistance, empirical coverage for MDR bacteria may be prudent $[10,13-15]$. In our group of surgical patients, MDR carbapenem-susceptible (so-called "3MRGN") isolates were found in 6 patients (23.1\%). All of them were known to be colonized with 3MRGN Enterobacteriaceae before or at onset of MT. However, only in 2 of these 6 patients 3MRGN E. coli was also detected in intraoperative swabs. In consequence, known colonization - and not necessarily infection - with 3MRGN Enterobacteriaceae was a risk factor for prolonged MT in our study. These findings are in accordance with studies that show that intensivists are more reluctant to de-escalate antimicrobial therapy in patients with known MDR colonization [16]. Retrospectively, the number of patients with relevant bacterial isolates at the site of infection and a clear indication for meropenem treatment was low (Table 3).

The in-ICU-mortality in patients with excessively prolonged MT was double as high as in the control group. It is likely that severe clinical condition prevented the intensivists from discontinuing meropenem. Of note, presence of systemic illness in complicated intraabdominal infections does not necessitate a longer course of antimicrobial therapy if source control is obtained [17]. The majority of surgical patients with excessively prolonged MT had numerous re-operations reflecting difficulties in source control. In fact, in all patients with peritonitis and excessively prolonged MT the source control 
Table 2 Analysis of potential risk factors for excessively prolonged meropenem therapy

\begin{tabular}{|c|c|c|c|c|c|c|c|}
\hline & & \multicolumn{3}{|c|}{ Univariate logistic regression } & \multicolumn{3}{|c|}{ Multivariate logistic regression } \\
\hline & & $O R$ & $95 \% \mathrm{Cl}$ & $P$-value & $O R$ & $95 \% \mathrm{Cl}$ & P-value \\
\hline \multirow[t]{3}{*}{ age } & $<50$ & 1 & & 0.44 & - & - & - \\
\hline & $50-70$ & 0.72 & $0.25-2.04$ & & & & \\
\hline & $\geq 70$ & 0.49 & $0.16-1.53$ & & & & \\
\hline \multirow[t]{2}{*}{ sex } & male & 1 & & 0.76 & - & - & - \\
\hline & female & 1.13 & $0.51-2.49$ & & & & \\
\hline \multirow[t]{2}{*}{ malignancy } & No & 1 & & 0.002 & 1 & & 0.84 \\
\hline & Yes & 3.5 & $1.57-7.82$ & & 1.14 & $0.32-4.06$ & \\
\hline \multirow[t]{2}{*}{ SAPS at admission } & $<40$ & 1 & & 0.33 & - & - & - \\
\hline & $\geq 40$ & 1.45 & $0.68-3.11$ & & & & \\
\hline \multirow[t]{3}{*}{ patient group } & medical & 1 & & $<0.001$ & 1 & & 0.31 \\
\hline & neurological & 2.41 & $0.63-9.30$ & & 2.79 & $0.65-11.92$ & \\
\hline & surgical & 8.36 & $2.67-26.17$ & & 2.46 & $0.50-11.98$ & \\
\hline \multirow[t]{2}{*}{ colonization with carbapenem-susceptible, MDR bacteria } & no & 1 & & 0.01 & 1 & & 0.004 \\
\hline & yes & 4.12 & $1.38-12.35$ & & 7.52 & $1.88-30.14$ & \\
\hline \multirow[t]{4}{*}{ type of infection } & pneumonia & 1 & & $<0.001$ & 1 & & $<0.001$ \\
\hline & peritonitis & 21.60 & $5.05-92.35$ & & 16.96 & $2.95-97.49$ & \\
\hline & mediastinitis & 10.12 & $1.96-52.41$ & & 6.27 & $0.81-48.76$ & \\
\hline & unclear focus & 0.94 & $0.27-3.24$ & & 0.77 & $0.21-2.84$ & \\
\hline
\end{tabular}

Full model containing all variables with at least some evidence of association $(p<0.1)$ with the outcome in univariate regression analysis Abbreviations: MDR multidrug-resistant; OR: odds ratio; $95 \% \mathrm{Cl}$ : 95\% confidence Interval

was considered as inadequate by the intensivists in charge. Inability to obtain source control is one of the main determinants of poor outcome [15]. However, prolonged broad-spectrum antimicrobial therapy is not likely to contribute to source control $[18,19]$. There is a growing body of evidence that prolonged antimicrobial therapy is not beneficial for critically ill patients (reviewed in [20]). This might be particularly true for broad-spectrum antimicrobials where disadvantages of antibiotic therapy might outweigh unlikely benefits for the patient [21].
Our study has several limitations. It is a single centre study in a tertiary care hospital and our experience might not be representative for all ICU departments. The retrospective nature of the study does not allow assessment of the contribution of extensively prolonged MT to clinical outcome. Based on our definition of cases and controls, the data can be used to identify risk factors for excessively prolonged use of meropenem ( $>28$ days) compared to guideline adherent use ( $\leq 14$ days). However, we cannot draw conclusions on risk factors for slightly longer use than recommended by guidelines (i.e.

Table 3 Positive bacterial culture results from sterile sites at onset and during the course of prolonged meropenem therapy

\begin{tabular}{|c|c|c|}
\hline Intraoperative cultures (abdominal, thoracic) & blood cultures & CSF, brain tissue \\
\hline $\begin{array}{l}\text { Enterococcus faecium, } \mathrm{n}=7 \\
\text { Enterococcus faecalis, } n=6 \\
\text { Stenotrophomonas maltophilia, } \mathrm{n}=6 \\
\text { multidrug-resistant, carbapenem-susceptible Escherichia coli, } n=2^{\text {a }} \\
\text { Enterobacter cloacae complex, } n=2 \\
\text { Coagulase-negative staphylococci, } n=2 \\
\text { Pseudomonas aeruginosa, } n=1 \\
\text { Proteus mirabilis, } n=1 \\
\text { Proteus vulgaris, } n=1 \\
\text { Klebsiella pneumoniae, } n=1 \\
\text { Escherichia coli (non } M R G N \text { ), } n=1 \\
\text { Staphylococcus aureus, } n=1 \\
\text { Enterococcus gallinarum, } n=1\end{array}$ & $\begin{array}{l}\text { E. faecalis, } n=1 \\
\text { E. faecium, } n=1 \\
\text { Vancomycin-resistant } \\
\text { Enterococcus faecium, } \\
n=1 \\
\text { E. aerogenes, } n=1 \\
\text { E. cloacae, } n=1 \\
\text { S. maltophilia, } n=1 \\
\text { multidrug-resistant, } \\
\text { carbapenem-resistant } \\
\text { P.aeruginosa, } n=1\end{array}$ & $\begin{array}{l}\text { Staphylococcus aureus, } \mathrm{n}=1 \\
\text { Staphylococcus epidermidis, } \\
n=1 \\
\text { Proteus mirabilis, } n=1 \\
\text { Bacteroides fragilis, } n=1\end{array}$ \\
\hline
\end{tabular}

aisolates that require unequivocally carbapenem therapy 
14-28 days). This group of patients is surely more heterogeneous than the cases in this study and should be included in the focus of future, larger studies.

Due to the small number of patients the power of the study was low, as reflected by wide $95 \%$ confidence intervals and several potential risk factors may not have been identified. Due to the low number of patients it was not possible to study the emergence of carbapenemresistant (so-called 4MRGN) microorganisms under prolonged MT. However, detection of carbapenemresistant E. coli and E. cloacae isolates after prolonged MT in one patient with known colonization with multidrug-resistant carbapenem-susceptible isolates and the emergence of carbapenem-resistant $P$. aeruginosa in another patient are worrying signs [22, 23].

\section{Conclusion}

Surgical patients with persistent peritonitis are at risk for excessively prolonged carbapenem therapy. Antimicrobial stewardship programmes should target this patient group to prevent overuse of last resort antimicrobials.

\begin{abstract}
Abbreviations
CSF: Cerebrospinal fluid; ICU: Intensive care unit; IDSA: Infectious Diseases Society of America; LOS: Length of stay; MDR: Multidrug-resistant; MRGN: Multidrug-resistant Gram-negative bacteria; MRSA: Methicillin-resistant S. aureus; MT: Meropenem therapy; OR: Odds ratio; SAPS: Simplified Acute Physiology Score; VRE: vancomycin-resistant enterococci
\end{abstract}

\section{Acknowledgements}

Not applicable.

\section{Funding}

No external funding was required for this retrospective study.

\section{Availability of data and materials}

The data used during the current study available from the corresponding author on reasonable request (juri.katchanov@icloud.com).

\section{Authors' contributions}

$\mathrm{JK}, \mathrm{BK}$, and CR conceived of the study, participated in the design of the study, collection of data, and drafting and revision of the manuscript. FM, JJ, CK, KS and HR participated in the design of the study, collection of data, preliminary statistical analysis, and initial drafting of the manuscript. KW, DW, SK participated in the design of the study, carried out the statistical analyses reported, and drafted, revised and finalised the manuscript. AL and MB participated in conception of the study and revision of the final manuscript. All authors read and approved the final manuscript.

\section{Competing interests}

The authors declare that they have no competing interests.

\section{Consent for publication}

Not applicable.

\section{Ethics approval and consent to participate}

The Ethics Committee of the Hamburg Chamber of Physicians approved the protocol and waived the need to obtain consent for the collection, analysis, and publication of the retrospectively obtained and anonymized data for this non-interventional study.

\section{Author details}

${ }^{1}$ Department of Intensive Care Medicine, University Medical Center Hamburg-Eppendorf, Martinistr. 52, 20246 Hamburg, Germany. ${ }^{2}$ Division of Infectious Diseases and Tropical Medicine, First Medical Department,
University Medical Center Hamburg-Eppendorf, Hamburg, Germany. ${ }^{3}$ Department of Medical Microbiology, Virology and Hygiene, University Medical Center Hamburg-Eppendorf, Hamburg, Germany. ${ }^{4}$ Hospital Pharmacy, University Medical Center Hamburg-Eppendorf, Hamburg, Germany. ${ }^{5}$ Infectious Disease Epidemiology, Bernhard-Nocht-Institute for Tropical Medicine, Hamburg, Germany.

Received: 27 October 2016 Accepted: 27 January 2017

Published online: 08 February 2017

\section{References}

1. Kollef MH. Bench-to-bedside review: antimicrobial utilization strategies aimed at preventing the emergence of bacterial resistance in the intensive care unit. Crit Care. 2005;9:459-64.

2. Daneman N, Gruneir A, Bronskill SE, Newman A, Fischer HD, Rochon PA, Anderson GM, Bell CM. Prolonged antibiotic treatment in long-term care: role of the prescriber. JAMA Intern Med. 2013;173:673-82.

3. Sanden L, Paul M, Leibovici L, Andreassen S. Quantifying the associations between antibiotic exposure and resistance - a step towards personalised antibiograms. Eur J Clin Microbiol Infect Dis. 2016. [Epub ahead of print]

4. Leibovici L, Paul M, Garner P, Sinclair DJ, Afshari A, Pace NL, Cullum N, Williams HC, Smyth A, Skoetz N, Del Mar C, Schilder AG, Yahav D, Tovey D. Addressing resistance to antibiotics in systematic reviews of antibiotic interventions. J Antimicrob Chemother. 2016;71:2367-9.

5. Dalhoff K, Abele-Horn M, Andreas S, Bauer T, von Baum H, Deja M, Ewig S, Gastmeier P, Gatermann S, Gerlach H, Grabein B, Höffken G, Kern WW Kramme E, Lange C, Lorenz J, Mayer K, Nachtigall I, Pletz M, Rohde G, Rosseau S, Schaaf B, Schaumann R, Schreiter D, Schütte $H$, Seifert $H$, Sitter $H$, Spies C, Welte T, German Society for Anaesthesiology and Intensive Care Medicine; German Society for Infectious Diseases; German Society for Hygiene and Microbiology; German Respiratory Society; Paul-Ehrlich-Society for Chemotherapy. [Epidemiology, diagnosis and treatment of adult patients with nosocomial pneumonia. S-3 guideline of the German society for anaesthesiology and intensive care medicine, the German society for infectious diseases, the German society for hygiene and microbiology, the German respiratory society and the Paul-Ehrlich-society for chemotherapy]. Pneumologie. 2012;66:707-65.

6. Kalil AC, Metersky ML, Klompas M, Muscedere J, Sweeney DA, Palmer LB, Napolitano LM, O'Grady NP, Bartlett JG, Carratalà J, El Solh AA, Ewig S, Fey PD, File TM Jr, Restrepo MI, Roberts JA, Waterer GW, Cruse P, Knight SL, Brozek JL. Management of Adults With Hospital-acquired and Ventilatorassociated Pneumonia: 2016 Clinical Practice Guidelines by the Infectious Diseases Society of America and the American Thoracic Society. Clin Infect Dis. 2016. [Epub ahead of print]

7. Wagenlehner FM, Schmiemann G, Hoyme U, Fünfstück R, Hummers-Pradier E, Kaase M, Kniehl E, Selbach I, Sester U, Vahlensieck W, Watermann D, Naber KG. [National S3 guideline on uncomplicated urinary tract infection: recommendations for treatment and management of uncomplicated community-acquired bacterial urinary tract infections in adult patients]. Urologe A. 2011;50:153-69.

8. Eckmann C. Antibiotic therapy of intra-abdominal infections in the era of multiresistance. Chirurg. 2016;87:26-33.

9. Sawyer RG, Claridge JA, Nathens AB, Rotstein OD, Duane TM, Evans HL, Cook CH, O'Neill PJ, Mazuski JE, Askari R, Wilson MA, Napolitano LM, Namias N, Miller PR, Dellinger EP, Watson CM, Coimbra R, Dent DL, Lowry SF, Cocanour CS, West MA, Banton KL, Cheadle WG, Lipsett PA, Guidry CA, Popovsky K. Trial of short-course antimicrobial therapy for intraabdominal infection. N Engl J Med. 2015:372:1996-2005.

10. Sartelli M, Catena F, Ansaloni L, Coccolini F, Di Saverio S, Griffiths EA. Duration of antimicrobial therapy in treating complicated intra-abdominal infections: a comprehensive review. Surg Infect (Larchmt). 2016;17:9-12.

11. Riccio LM, Popovsky KA, Hranjec T, Politano AD, Rosenberger LH, Tura KC, Sawyer RG. Association of excessive duration of antibiotic therapy for intra-abdominal infection with subsequent extra-abdominal infection and death: a study of 2,552 consecutive infections. Surg Infect (Larchmt). 2014;15:417-24.

12. Solomkin JS, Mazuski JE, Bradley JS, et al. Diagnosis and management of com- plicated intra-abdominal infection in adults and children: guidelines by the surgical in-fection society and the infectious diseases society of america. Clin Infect Dis. 2010;50:133-64. 
13. Montravers P, Gauzit R, Muller C, Marmuse JP, Fichelle A, Desmonts JM. Emergence of antibiotic-resistant bacteria in cases of peritonitis after intraabdominal surgery affects the efficacy of empirical antimicrobial therapy. Clin Infect Dis. 1996;23:486-94.

14. Montravers P, Dufour G, Guglielminotti J, Desmard M, Muller C, Houissa H, Allou N, Marmuse JP, Augustin P. Dynamic changes of microbial flora and therapeutic consequences in persistent peritonitis. Crit Care. 2015;19:70.

15. Montravers P, Blot S, Dimopoulos G, Eckmann C, Eggimann P, Guirao X, Paiva JA, Sganga G, De Waele J. Therapeutic management of peritonitis: a comprehensive guide for intensivists. Intensive Care Med. 2016;42:1234-47.

16. De Waele JJ, Ravyts M, Depuydt P, Blot SI, Decruyenaere J, Vogelaers D. De-escalation after empirical meropenem treatment in the intensive care unit: fiction or reality? J Crit Care. 2010;25:641-6.

17. Rattan R, Allen CJ, Sawyer RG, Askari R, Banton KL, Claridge JA, Cocanour CS, Coimbra R, Cook CH, Cuschieri J, Dellinger EP, Duane TM, Evans HL, Lipsett PA, Mazuski JE, Miller PR, O'Neill PJ, Rotstein OD, Namias N. Patients with complicated intra-abdominal infection presenting with sepsis Do Not require longer duration of antimicrobial therapy. J Am Coll Surg. 2016;222:440-6.

18. Solomkin JS, Ristagno RL, Das AF, Cone JB, Wilson SE, Rotstein OD, Murphy $B S$, Severin KS, Bruss JB. Source control review in clinical trials of antiinfective agents in complicated intra-abdominal infections. Clin Infect Dis. 2013:56:1765-73.

19. De Waele JJ. Abdominal sepsis. Curr Infect Dis Rep. 2016;18:23.

20. Vincent JL, Bassetti M, François B, Karam G, Chastre J, Torres A, Roberts JA, Taccone FS, Rello J, Calandra T, De Backer D, Welte T, Antonelli M. Advances in antibiotic therapy in the critically ill. Crit Care. 2016;20:133.

21. Spellberg B. Antibiotic judo: working gently with prescriber psychology to overcome inappropriate use. JAMA Intern Med. 2014;174:432-3.

22. Su CH, Wang JT, Hsiung CA, Chien L, Chi CL, Yu HT, Chang FY, Chang SC. Increase of carbapenem-resistant acinetobacter baumannii infection in acute care hospitals in Taiwan: association with hospital antimicrobial usage. PLoS One. 2012;7:e37788.

23. Gharbi M, Moore LS, Gilchrist M, Thomas CP, Bamford K, Brannigan ET, Holmes $\mathrm{AH}$. Forecasting carbapenem resistance from antimicrobial consumption surveillance: lessons learnt from an OXA-48-producing klebsiella pneumoniae outbreak in a west London renal unit. Int J Antimicrob Agents. 2015:46:150-6.

\section{Submit your next manuscript to BioMed Central and we will help you at every step:}

- We accept pre-submission inquiries

- Our selector tool helps you to find the most relevant journal

- We provide round the clock customer support

- Convenient online submission

- Thorough peer review

- Inclusion in PubMed and all major indexing services

- Maximum visibility for your research

Submit your manuscript at www.biomedcentral.com/submit

) Biomed Central 